\title{
Grid-Connected PV Solar Energy Converter with Active and Reactive Power Control
}

\author{
Roberto F. Coelho, Artur Pagnoncelli Galbiatti and Denizar Cruz Martins \\ INEP, Power Electronics Institute, Federal University of Santa Catarina, Florianópolis (SC) 88040-970, Brazil
}

Received: August 14, 2013 / Accepted: October 21, 2013 / Published: February 28, 2014.

\begin{abstract}
This work proposes a $12 \mathrm{~kW}$ three-phase grid-connected single stage PWM DC-AC converter destined to process the energy provided by a photovoltaic array composed of $57 \mathrm{KC} 200 \mathrm{GT}$ PV modules with high power factor for any solar radiation. The PWM inverter modeling and the control strategy, using $d q 0$ transformation, are proposed in order to also allow the system operation as an active power filter, capable to compensate harmonic components and react power generated by the non-linear loads connected to the mains grid. An input voltage clamping technique is proposed to impose the photovoltaic operation on the maximum power point. Simulation and experimental results are presented to validate the proposed methodology for grid connected photovoltaic generation system.
\end{abstract}

Key words: Active and reactive power, $d q 0$ transformation, grid-connected PV systems, three-phase DC-AC PWM converter.

\section{Introduction}

For decades the electrical energy matrix was based almost exclusively on non-renewable sources: oil, gas, coal and nuclear power plant. The energy crisis, in 1973, associated to the government incentive and cost reduction, allowed the gradual employment of RES (renewable energy sources) as a non-pollutant and alternative sources of electrical energy.

Firstly, PV (photovoltaic) systems were widely used to provide energy for remote areas, in standalone applications. However, with the power electronic development and the possibility to connected photovoltaic systems to the mains, resulting in the grid-connected photovoltaic systems [1,2].

Commonly, the grid-connection is achieved by the employment of power converters, capable to process the photovoltaic generated energy and to provide it for the grid' ensuring high power factor and the grid current quality $[3,4]$. In this context, several papers have been published, concerning the study of topologies and

Corresponding author: Denizar Cruz Martins, professor, research fields: power electronics, dc-ac converter and power quality. E-mail: denizar@inep.ufsc.br. control strategies for three-phase converters applied to grid-connection [5-9].

In this paper, a $12 \mathrm{~kW}$ three-phase grid-connected single stage PWM DC-AC converter destined to process the energy provided by a photovoltaic array composed of 57 KC200GT photovoltaic modules (Fig. 1) is presented. The main features associated to the proposed system are:

- capability to supply any AC loads, including the non-linear ones;

- provident of active power to the main grid;

- active power filter function-compensation of instantaneous reactive power caused by non-linear loads connected to the system $[10,11]$;

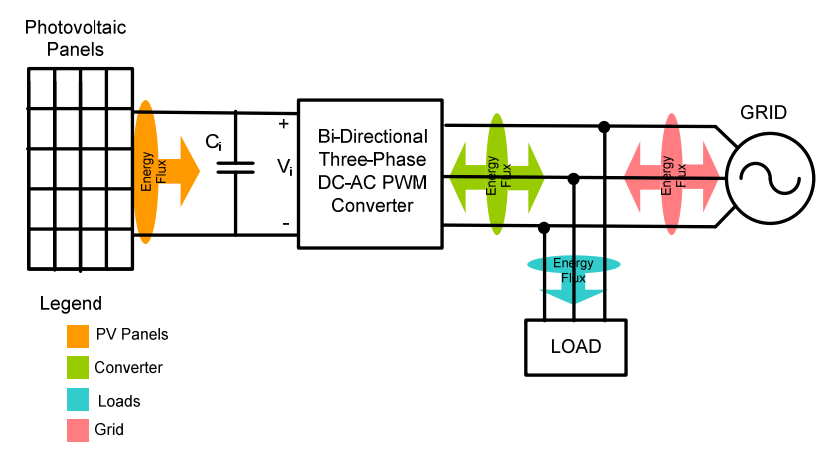

Fig. 1 Proposed three-phase photovoltaic power system. 
- operation near unity power factor for any solar radiation;

- UPS function for any kind of load;

- energy flow control between the photovoltaic array and the grid;

- maximum power point tracking accomplishment, ensuring the photovoltaic array operation on the optimal point.

In order to reach all these purposes, a complete system analysis is presented, including the converter mathematical modeling using $d q 0$ transformation, a control strategy for grid current and dc bus voltage compensation and both, simulation and experimental results, validating the system theoretical study.

\section{Photovoltaic Array Design}

A photovoltaic array is an interconnection of modules made up of many PV cells in parallel or series to obtain the desired power. In this paper a PV array using Kyocera KC200 was designed to validate the proposed methodology. The Kyocera KC200 module specifications are shown in Table 1.

The array was connected in a proper series-parallel configuration as shown in Fig. 2. Table 2 shows the main characteristics of the PV array, which was designed to close near $500 \mathrm{~V}$ photovoltaic output voltage and power of $11.4 \mathrm{~kW}$ To simulate the PV array, it was used to the equivalent circuit shown in Fig. 3.

In the proposed photovoltaic array modeling, the DC voltage source represents the open circuit voltage of all series photovoltaic modules, while the diode imposes its semiconductor characteristic.

\section{Modeling of the Converter}

The converter modeling is relatively simple and it is accomplished through $d q 0$ transformation. To apply

Table 1 Kyocera KC200 electrical specifications.

\begin{tabular}{lc}
\hline Maximum power & $200 \mathrm{~W}$ \\
\hline Maximum power voltage & $26.3 \mathrm{~V}$ \\
Maximum power current & $7.61 \mathrm{~A}$ \\
Open circuit voltage & $32.9 \mathrm{~V}$ \\
Short circuit current & $8.21 \mathrm{~A}$ \\
\hline
\end{tabular}

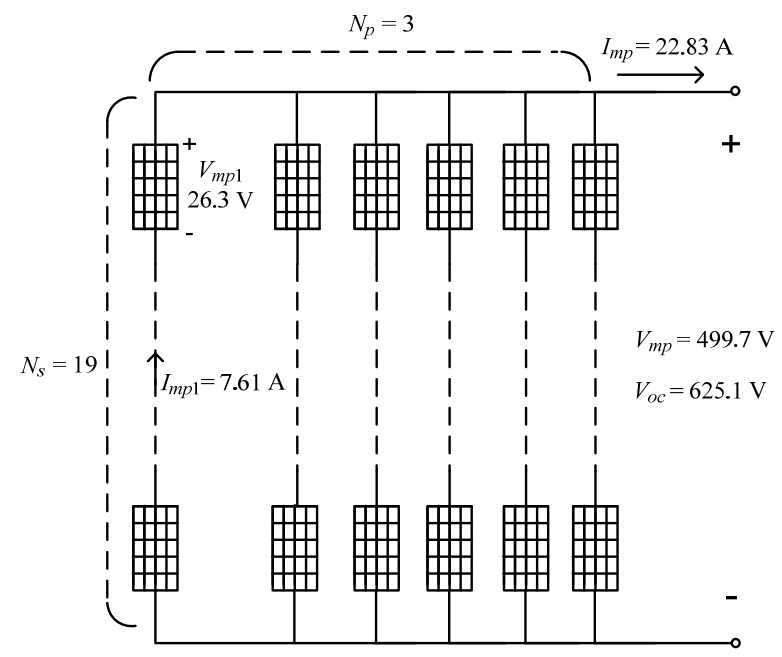

Fig. 2 PV array designed.

Table 2 PV array specifications using Kyocera KC200 panels.

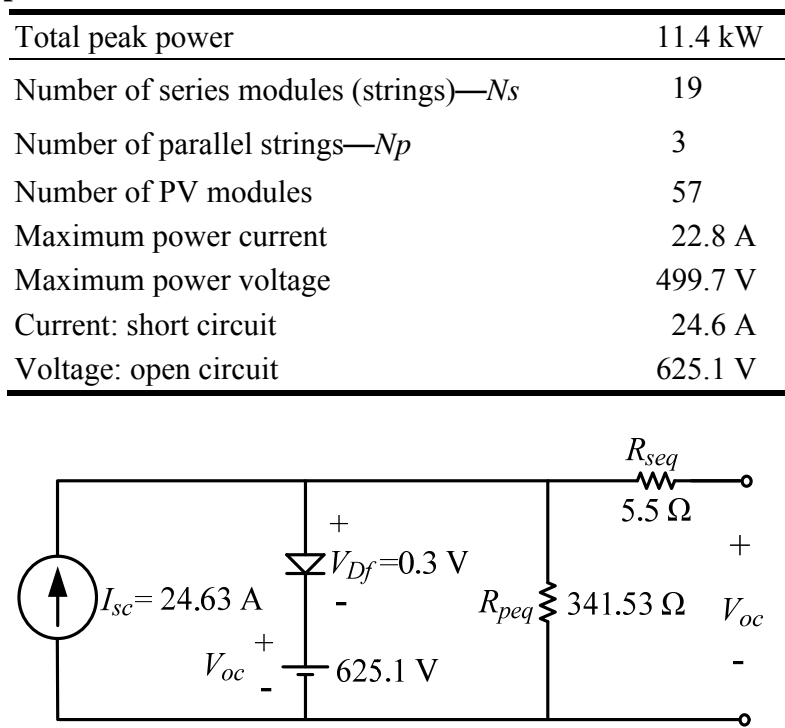

Fig. 3 PV array simulated circuit.

the proposed methodology it is necessary to obtain the voltage and current modeling [6].

\subsection{The Three-phase Converter}

The converter proposed in this work is a three-phase bi-directional DC-AC converter with PWM modulation using six power switches. The simplified electrical diagram of the converter is shown in Fig. 4.

The bi-directional characteristic of the converter is very important in this proposed photovoltaic system, because it allows the processing of active and reactive power from the generator to the load and vice-versa, 


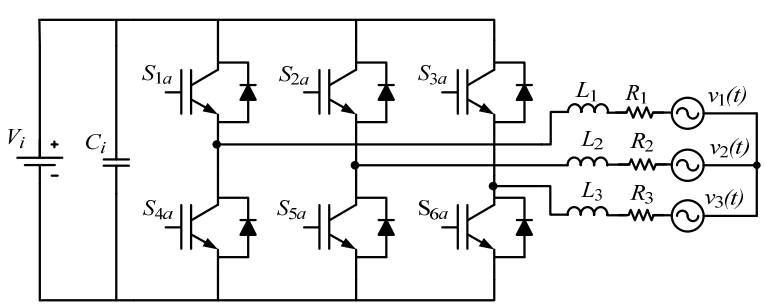

Fig. 4 Bi-directional DC-AC PWM converter.

depending on the application. Thus, with an appropriate control of the power switches it is possible to control the active and reactive power flow $[8,12]$.

\subsection{Voltage Control Modelling}

The purpose of this modeling is to accomplish the active input voltage clamping $V_{i}(t)$. This active clamping brings the following advantages:

- control of the power flow between grid and PV system;

- possibility to realize the MPPT (maximum power point tracking) of the PV panels.

The possibility of MPP operation is based on the constant voltage method that is achieved by keeping the voltage in the PV terminals constant and close to the MPP [13, 14]. In Fig. 5, an example of the current and voltage characteristics of a PV cell for different values of solar irradiation is presented.

Observing the MPP points (MPP line), it is possible to notice that the voltage values vary very little even when the intensity of the solar irradiation suffers great alterations. Concern to the temperature, fortunately, the region in Brazil, where this system is implemented, the temperature has no important variation during the day. So, the experimental tests show that this MPP technique can be used, in this case, without any problem.

With the voltage clamped in a value "inside" of the MPP Region, when a variation of the solar irradiation happens, the intensity of the PV cell current also changes; however, the output voltage of the PV cell will not be altered drastically.

Thus, it is necessary to obtain the transfer function of the input voltage $V_{i}$ as functions of the axis $d$ and $q$ currents.

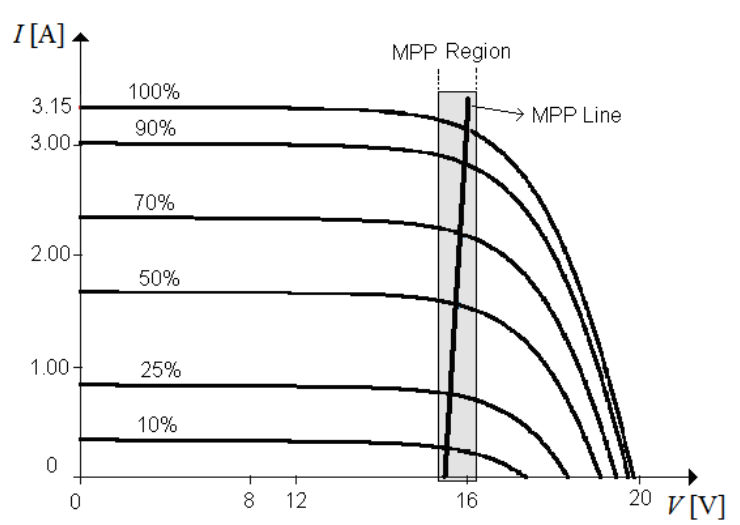

Fig. 5 Example of the current and voltage characteristics of a PV cell.

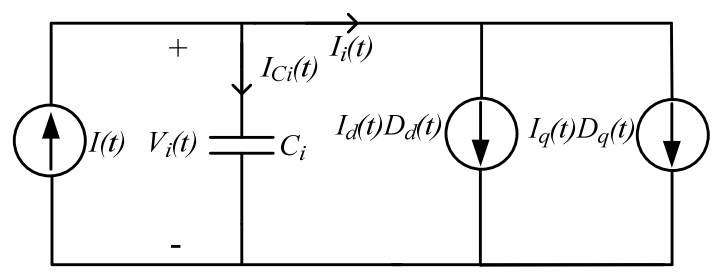

Fig. 6 Equivalent circuit seen by the DC side.

The control voltage across capacitor $C_{i}$ is obtained considering the DC input voltage shown in Fig. 4. The equivalent circuit in $d q 0$ axis, seen by the $\mathrm{DC}$ side, is shown in Fig. 6.

In this equivalent circuit, $I(t)$ represents the current supplied by PV panels (1) and $I_{i}(t)$ represents the input inverter current (2). The transfer function between voltage $v_{i}(s)$ and input current of the inverter $i_{i}(s)$ is shown in Eq. (3).

$$
\begin{gathered}
I(t)=I_{C i}(t)+I_{i}(t) \\
I_{i}(t)=I_{d}(t) D_{d}(t)+I_{q}(t) D_{q}(t) \\
\frac{v_{i}(s)}{i_{C i}(s)}=-\frac{1}{s C_{i}}
\end{gathered}
$$

Developing and substituting appropriately the equations, it is possible to obtain the desired voltage control modeling. The equations $v_{i}(s)$ as function of the currents in axis $d$ and $q$ are shown in Eqs. (4) and (5), respectively.

$$
\begin{gathered}
\frac{v_{i}(s)}{i_{d}(s)}=\frac{1}{s C_{i}}\left[(-K L s)-2 K R+\frac{\sqrt{3}}{\sqrt{2}} \frac{V_{p}}{V_{i}}\right] \\
\frac{v_{i}(s)}{i_{q}(s)}=-\frac{\sqrt{2}}{\sqrt{3}} \frac{Q}{V_{i} V_{p}}\left[\frac{s L+2 R}{s C_{i}}\right]
\end{gathered}
$$


where,

$L, R$ - equivalent resistances and inductances;

$C_{i}$-input capacitor;

$V_{p}$-voltage peak of the grid;

$V_{i}$-input voltage;

$i_{d}, i_{q}-$ currents in the axis $\mathrm{d}$ and $\mathrm{q}$, respectively;

$P$-active power;

$Q$-reactive power.

$$
K=\frac{\sqrt{2}}{\sqrt{3}} \frac{P}{V_{p} \cdot V_{i}}
$$

\subsection{Current Control Modeling}

The modeling for the current control is obtained considering the $\mathrm{AC}$ output. When the circuit is observed from the AC output, it is possible to make some initial considerations that result in a simplified circuit [15], shown in Fig. 7. The line voltages are presented in Eq. (6) considering $L_{1}=L_{2}=L_{3}=L, R_{1}=$ $R_{2}=R_{3}=R$ and $D$ are the duty cycles.

$$
\left\{\begin{array}{l}
V_{12}(t)=L \frac{d I_{12}(t)}{d t}+D_{12}(t) V_{i}+R I_{12}(t) \\
V_{23}(t)=L \frac{d I_{23}(t)}{d t}+D_{23}(t) V_{i}+R I_{23}(t) \\
V_{31}(t)=L \frac{d I_{31}(t)}{d t}+D_{31}(t) V_{i}+R I_{31}(t)
\end{array}\right.
$$

Applying $d q 0$ transformation and developing the equations system (6), it is possible to find the differential Eq. (7), which describes the currents behavior in axis $d$ and $q$.

$$
\left\{\begin{array}{l}
\frac{d I_{d}(t)}{d t}=\omega I_{q}(t)+\sqrt{\frac{3}{2}} \frac{V_{p}}{L}-\frac{V_{i}}{L} D_{d}(t)-\frac{R I_{d}(t)}{L} \\
\frac{d I_{q}(t)}{d t}=-\omega I_{d}(t)-\frac{V_{i}}{L} D_{q}(t)-\frac{R I_{q}(t)}{L}
\end{array}\right.
$$

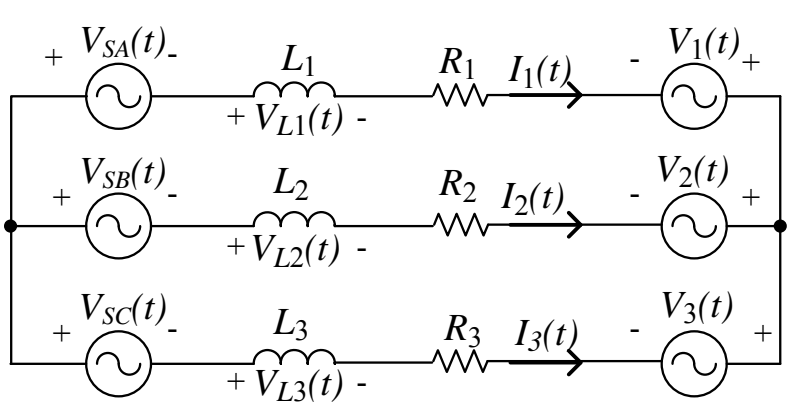

Fig. 7 Simplified circuit from AC output.
The direct axis current depends on the quadrature axis current and vice-versa. In order to decouple this dependence, a new duty cycle is defined and it is presented in Eq. (8).

$$
\left\{\begin{array}{l}
D_{d}^{\prime}(t)=D_{d}(t)-\frac{\omega L}{V_{i}} I_{q}(t) \\
D_{q}^{\prime}(t)=D_{q}(t)+\frac{\omega L}{V_{i}} I_{d}(t)
\end{array}\right.
$$

If $D_{d}(t)$ and $D_{q}(t)$ were isolated in Eq. (8), it is possible to rewrite Eq. (7) as follows:

$$
\left\{\begin{array}{l}
\frac{d I_{d}(t)}{d t}=\sqrt{\frac{3}{2}} \frac{V_{p}}{L}-\frac{V_{i}}{L} D^{\prime}{ }_{d}(t)-\frac{R I_{d}(t)}{L} \\
\frac{d I_{q}(t)}{d t}=-\frac{V_{i}}{L} D^{\prime}{ }_{q}(t)-\frac{R I_{q}(t)}{L}
\end{array}\right.
$$

Developing appropriately these equations, it is possible to obtain the differential equations that show the behavior of the currents in axis $d$ and $q$ as functions of the duty cycles. So, the transfer functions used in the design of the current controllers are shown in Eq. (10).

$$
\left\{\begin{array}{l}
\frac{i_{d}(s)}{d_{d}^{\prime}(s)}=-\frac{V_{i}}{s L+R} \\
\frac{i_{q}(s)}{d^{\prime}{ }_{q}(s)}=-\frac{V_{i}}{s L+R}
\end{array}\right.
$$

In this current control modeling, the line duty cycles $\left(D_{12}(t), D_{23}(t), D_{31}(t)\right)$ are used in all the equations. Nevertheless, to satisfy the PWM modulation, it is necessary to determine the phase duty cycles $\left(D_{1}(t)\right.$, $\left.D_{2}(t), D_{3}(t)\right)$. This is obtained by $\Delta / Y$ transformation shown in Eq. (11).

$$
\left[\begin{array}{l}
D_{1}(t) \\
D_{2}(t) \\
D_{3}(t)
\end{array}\right]=\left[\begin{array}{ccc}
1 / 3 & 0 & -1 / 3 \\
-1 / 3 & 1 / 3 & 0 \\
0 & -1 / 3 & 1 / 3
\end{array}\right]\left[\begin{array}{l}
D_{12}(t) \\
D_{23}(t) \\
D_{31}(t)
\end{array}\right]
$$

\section{Implementation of the Control Methodology}

Fig. 8 shows the diagram of the control methodology and the modulation of the proposed three-phase grid-connected PV system. The practical implementation of control strategy and a zero cross 


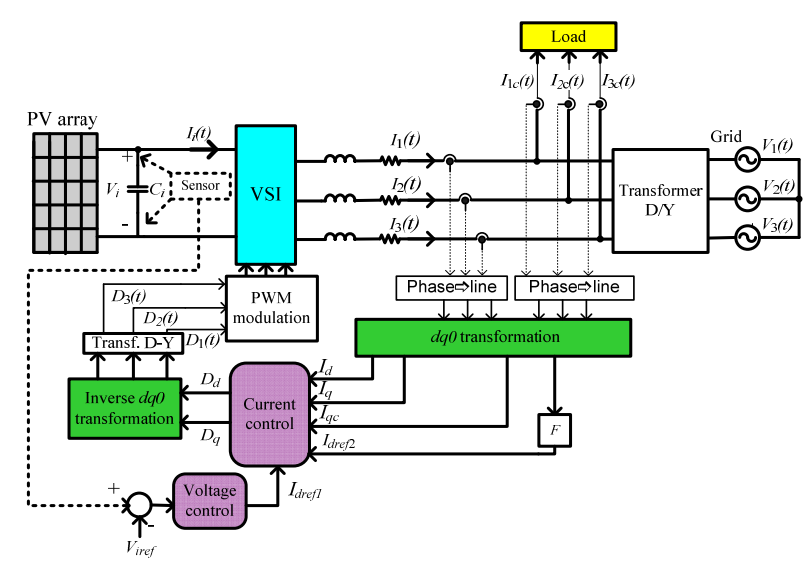

Fig. 8 Diagram of the control system.

detector circuit to make the synchronism with the grid have been implemented through DSP (digital signal processing) device.

As can be seen from Fig. 8, the inverter output currents $\left(I_{1}, I_{2}\right.$ and $\left.I_{3}\right)$ and the load currents $\left(I_{1 c}, I_{2 c}\right.$ and $\left.I_{3 c}\right)$ are acquired through sensors. In the line currents it is applied $d q 0$ transformation.

\subsection{Current Control Strategy}

To control the currents of the axis $d$, the current $I_{d}(t)$ and the reference currents $I_{d r e f 1}(t)$ and $I_{d r e f 2}(t)$ are used, according to Fig. 9. The sign $I_{d r e f 2}(t)$ represents the alternate portion of the current $I_{d c}(t)$ in the direct axis $d$ and it is obtained through a high-pass filter (Fig. 10) [16]. This strategy is necessary to compensate possible power unbalances in the system.

To control the currents of axis $q$ (Fig. 11), a reference signal $I_{q c}(t)$ is used to compensate the reactive power caused by the load connected to the system.

In the output of both controls ( $d$ and $q$ axis) it is necessary to accomplish an uncoupling in order to obtain the duty cycles $d_{d}(t)$ as function of $i_{d}(t)$ and $d_{q}(t)$ as function of $i_{q}(t)$.

\subsection{Voltage Control Strategy}

The voltage in the capacitor $C_{i}$ is compared with the reference voltage $V_{\text {iref }}$ and the error signal enters in the voltage controller, resulting in the signal $I_{\text {dref } 1}(t)$ (Fig. 12).

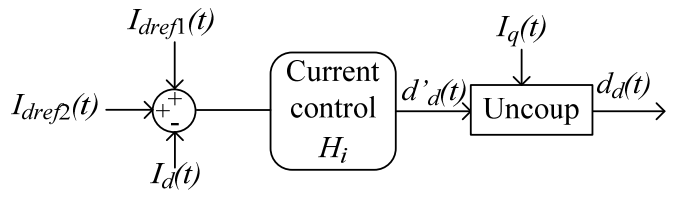

Fig. 9 Block diagram of the current control in the $d$ axis.

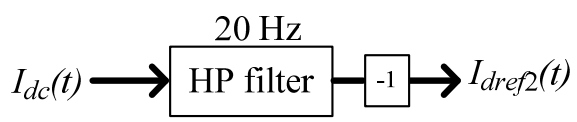

Fig. $10 I_{d r e f 2}(t)$ obtaining.

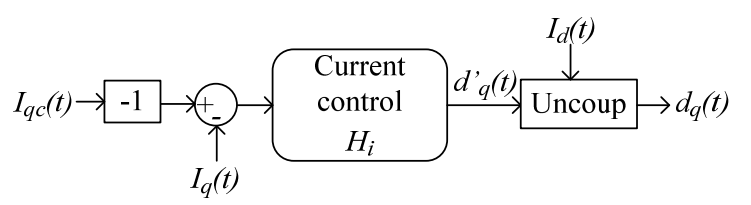

Fig. 11 Block diagram of the current control in the $q$ axis.

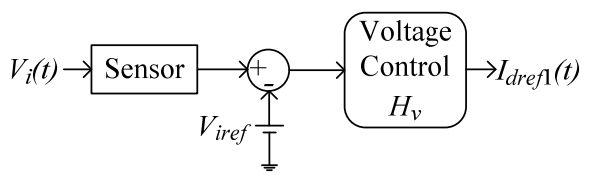

Fig. 12 Diagram of the voltage regulator.

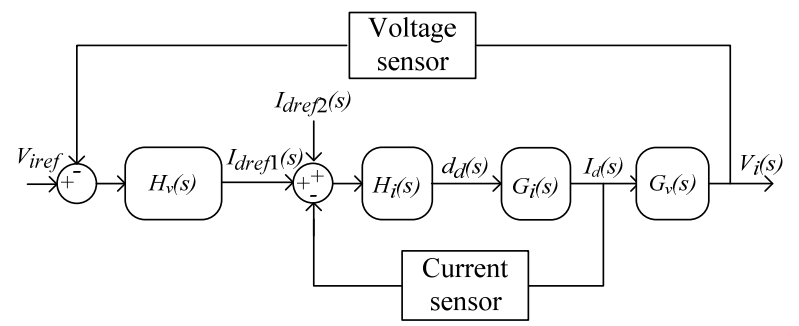

Fig. 13 Block diagram of the voltage control.

The signal $I_{\text {dref } 1}(t)$ is used as one of the references in the current control loop of the direct axis $d$, guaranteeing that the voltage $V_{i}(t)$ keeps clamped at the desired value, as shown in Fig. 13.

\section{Simulation Results}

Numerical simulations were accomplished for different situations of loads and solar radiations. The simulations of the loads connected in the system are linear and non-linear types.

For simulating, it was used the parameters of the converter shown in Table 3. The simulation with linear loads was done and good results were obtained to several load parameters. Fig. 14 presents the behavior of current and voltage in phase 1 when the PV array begins sending power to the system. In this figure it is 
Table 3 Converter simulation parameters.

\begin{tabular}{ll}
\hline Parameters & Description \\
\hline$P=11.4 \mathrm{kVA}$ & Converter power \\
$V_{i}=500 \mathrm{~V}$ & Input voltage (DC) \\
$V_{\text {out }}=127 \mathrm{~V}$ & RMS output voltage (grid) \\
$f_{r}=60 \mathrm{~Hz}$ & Grid frequency \\
$f_{s}=20 \mathrm{kHz}$ & Commutation frequency \\
$R=0.57 \Omega$ & Output inverter equivalent resistor \\
$L=1.92 \mathrm{mH}$ & Output inverter equivalent inductance \\
$C_{i}=4.7 \mathrm{mF}$ & Input inverter capacitor \\
\hline
\end{tabular}

also shown the output currents of the converter and the load. It is possible to see that the PV array is supplying almost the entire current to the load, so the current in the phase 1 of the grid has a small value.
The same currents waveforms shown in Fig. 14 are also seen in Fig. 15 at the instant where the current of the PV array increases from $10 \mathrm{~A}$ to $20 \mathrm{~A}$. The excess of the energy that does not consume by the load is injected into the grid with high quality, as shown in Fig. 15. In this moment, the grid input current waveform is sinusoidal and is $180^{\circ}$ out of phase to the grid voltage. In other words, part of the energy from the PV array supplies the RL load and the additional energy is inserted into the grid.

To show a better performance of the proposed system, the results considering non-linear loads connected to the system are presented. The non-linear

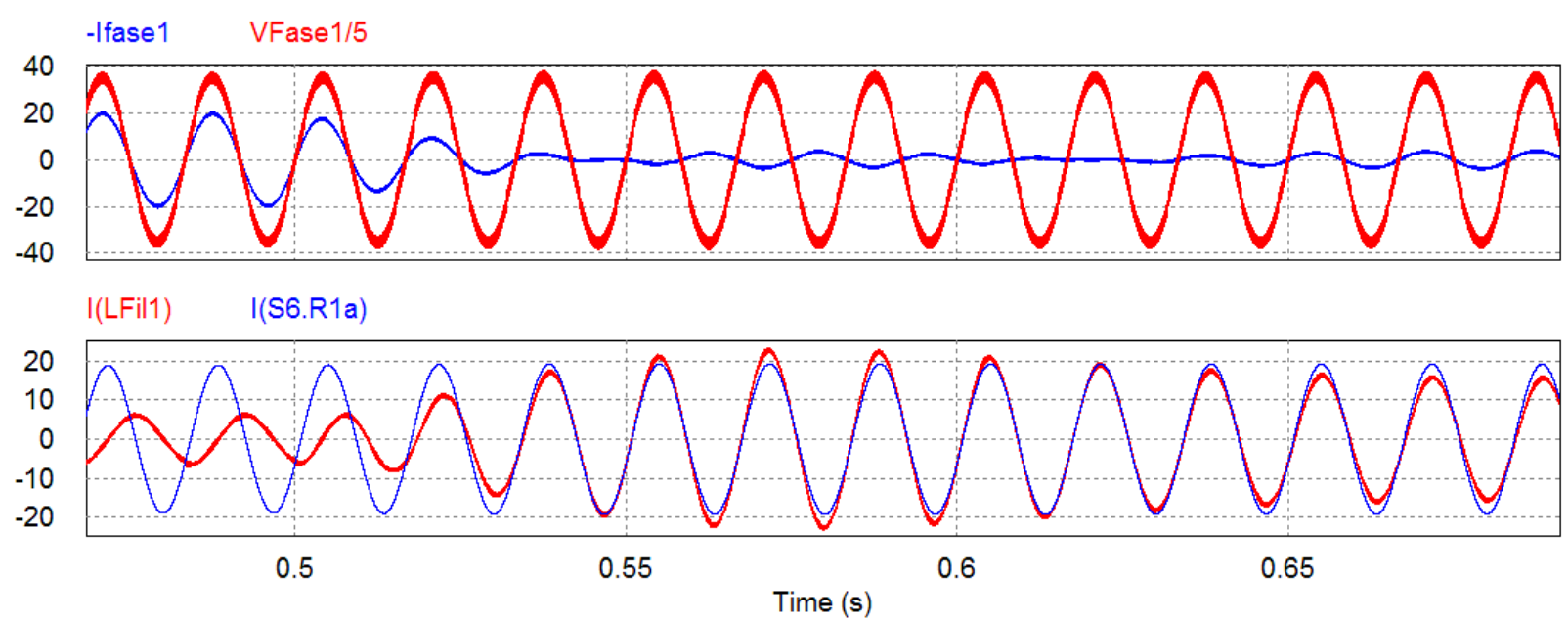

Fig. 14 Linear load simulation: Ipv = 10 A-grid voltage and current (phase 1), load current and output inverter current (phase 1).

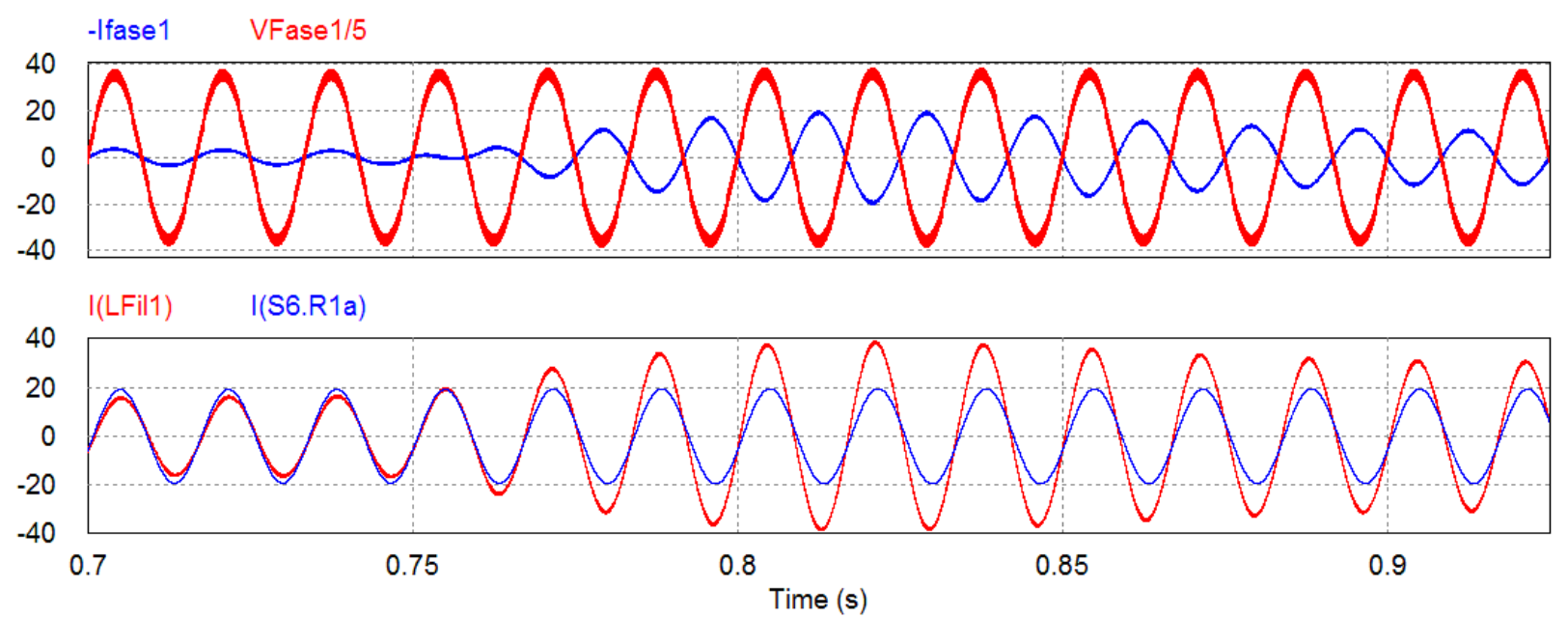

Fig. 15 Linear load simulation: $I p v=20$ A-grid voltage and current (phase 1), load current and output inverter current (phase 1). 
load is a three-phase bridge rectifier with $\mathrm{RC}$ output, shown in Fig. 16. With this kind of load the performance of the reactive power compensation and harmonics current elimination is better observed when tests are done [17].

The simulation presents the behavior of the system for several situations of abrupt variations of the current supplied by the PV panels. Fig. 17 shows in the phase 1 the grid voltage, grid current, load current, output inverter current and input voltage $V_{i}(t)$ for the moment that the PV current is null. Observing the current and voltage of the grid there is no processing energy from the sun, it is noted that the current is in phase with the voltage. During this period, the converter is operating only to correct the power factor of the system.

Fig. 18 shows, in the phase 1 , the grid voltage, grid current, load current and output inverter current behavior, when a variation of the current supplied by the PV panels occurs at the instant $t=0.75 \mathrm{~s}$. Even with non-linear load, the grid current waveform is sinusoidal and is $180^{\circ}$ out of phase to the grid voltage. This situation means that the grid is receiving energy from the PV panels.

Fig. 19 shows the behavior of the current and voltage in phase 1 of the grid, when another abrupt variation of the current supplied by PV panels occurs. In the absence of the PV panel energy, the converter only acts as an active power filter. The inverter output current and the load current are also shown in Fig. 19.

Even with this abrupt variation, the voltage control maintains the desired level of the DC Bus (500 V) with high power factor. The input voltage $V_{i}(t)$ behavior is shown in Fig. 20.

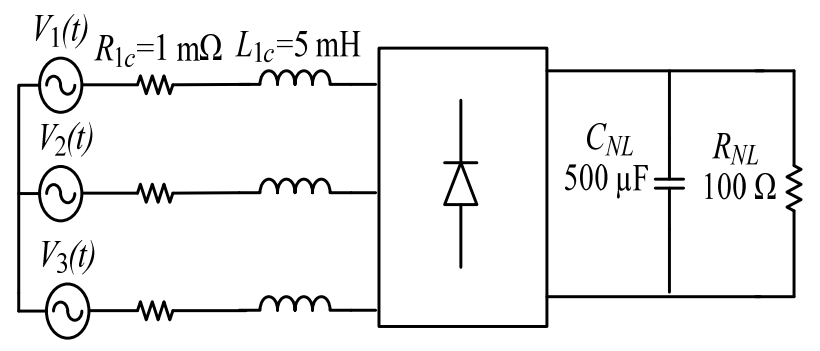

Fig. 16 Non-linear load simulated.
To validate the structure operation as active power filter, Fig. 21 shows the grid and load current harmonic spectrum in the phase 1 . It has been verified that using the proposed control strategy, it is possible to eliminate the harmonic components of the grid current.

\section{Experimental Results}

To demonstrate the feasibility of the discussed PV system, a prototype was designed and implemented following the specifications presented in Table 2 and 3. Fig. 22 depicts in the phase 1 the utility voltage $\left(V_{U t i l i t y}\right)$ and utility current $\left(I_{S}\right)$ with the system operating just in the active power line conditioning mode (cloudy day or night) using only linear load $\left(I_{L}\right)$. Fig. 22 shows that the shift angle between voltage and current is compensated satisfactorily.

Fig. 23 depicts, in the phase 1, the utility voltage $\left(V_{U t i l i t y}\right)$, inverter current $\left(I_{\text {inverter }}\right)$ and utility current $\left(I_{S}\right)$ using non-linear load $\left(I_{L}\right)$. The THD of $I_{L}$ is $27.5 \%$. The system is also operating just in the active power line conditioning mode. Fig. 24 shows the utility current harmonic spectrum in the phase 1 , where the THD of the utility current $\left(I_{S}\right)$ is $4 \%$. From the presented results it is noted that the proposed system may properly compensate current harmonic components.

Fig. 25 shows the behavior of the utility voltage $\left(V_{U t i l i t y}\right)$, utility current $\left(I_{S}\right)$ in the phase 1 , the load current $\left(I_{L}\right)$ and the input voltage $V_{i}(t)$ with non-linear load, which the THD of load current $\left(I_{L}\right)$, in this case, is $75 \%$ for a crest factor of 3.09 . When this non-linear load is employed, the system must operate with highest performance, since it needs to compensate a high harmonic distortion. For this situation, after the system compensation, the THD of the utility current $\left(I_{S}\right)$ is around 5\%, as shown in Fig. 26.

Fig. 27 shows the utility voltage and the utility current in the phase 1 , with the system only supplying power to the utility grid $(T H D=2.5 \%$ and $P F=0.998)$. In this case no load is connected in the PV system. The presented test scenario confirms that the system may control the power flow from the photo-voltaic array to the main grid. 


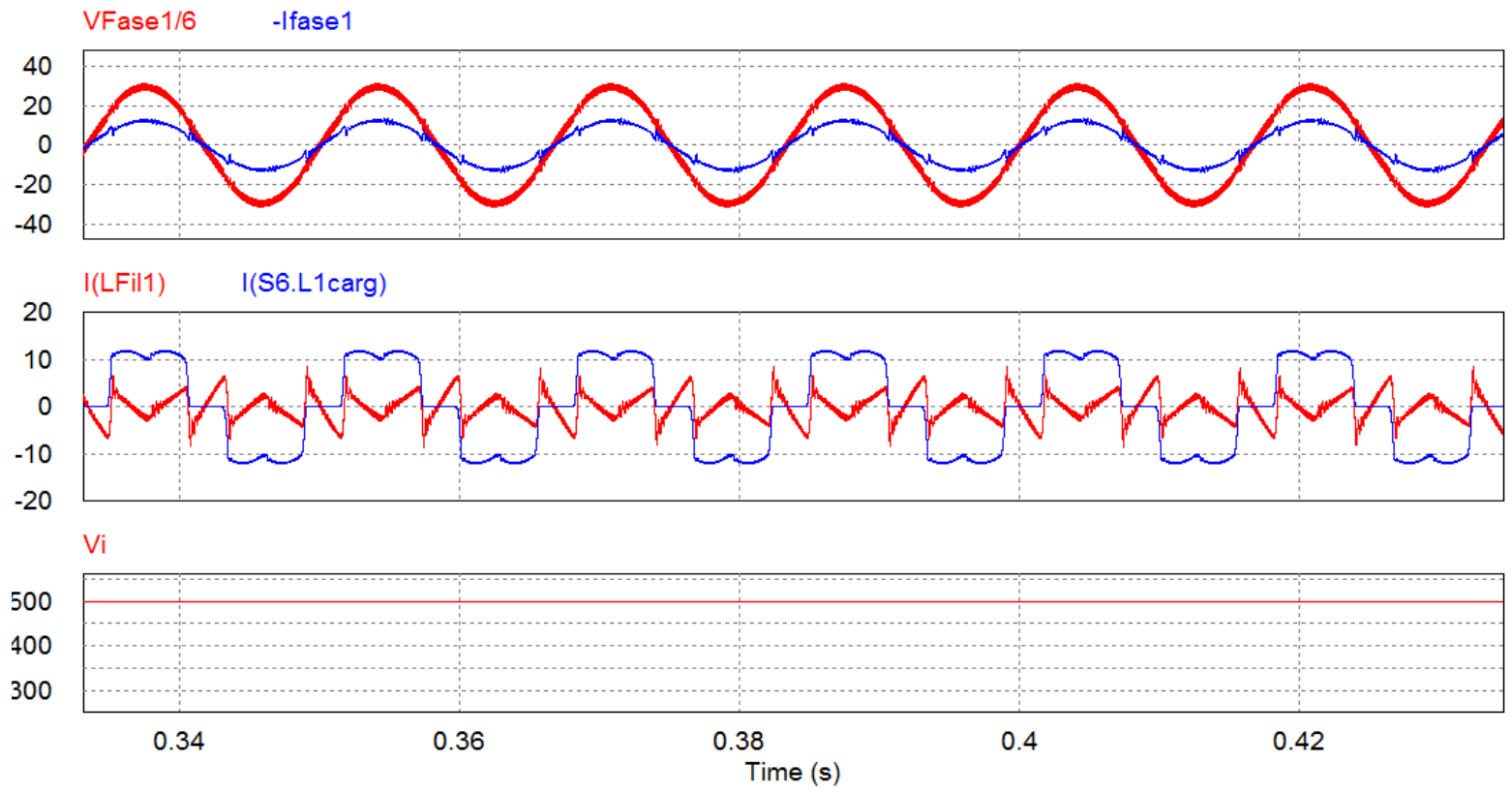

Fig. 17 Grid voltage and current (phase 1), load current and output inverter current (phase 1); and input voltage.

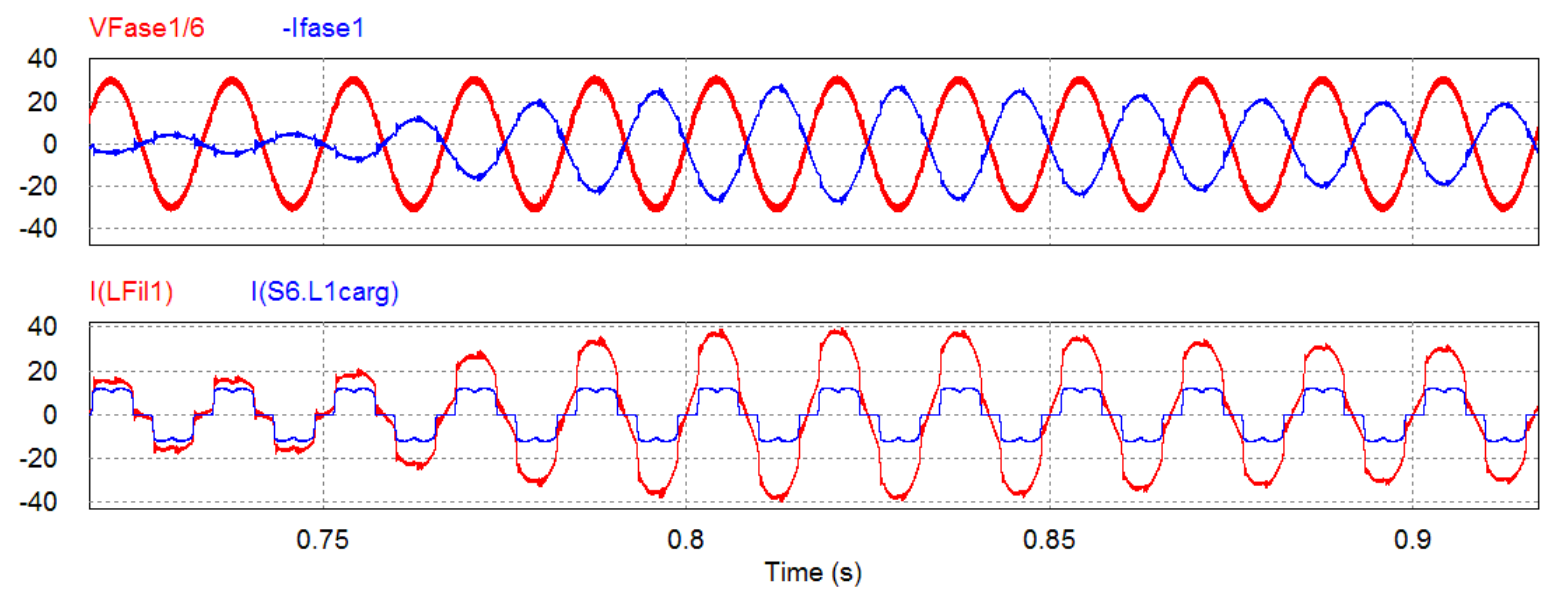

Fig. 18 No-linear load simulation: grid voltage and current (phase 1), load current and output inverter current (phase 1).

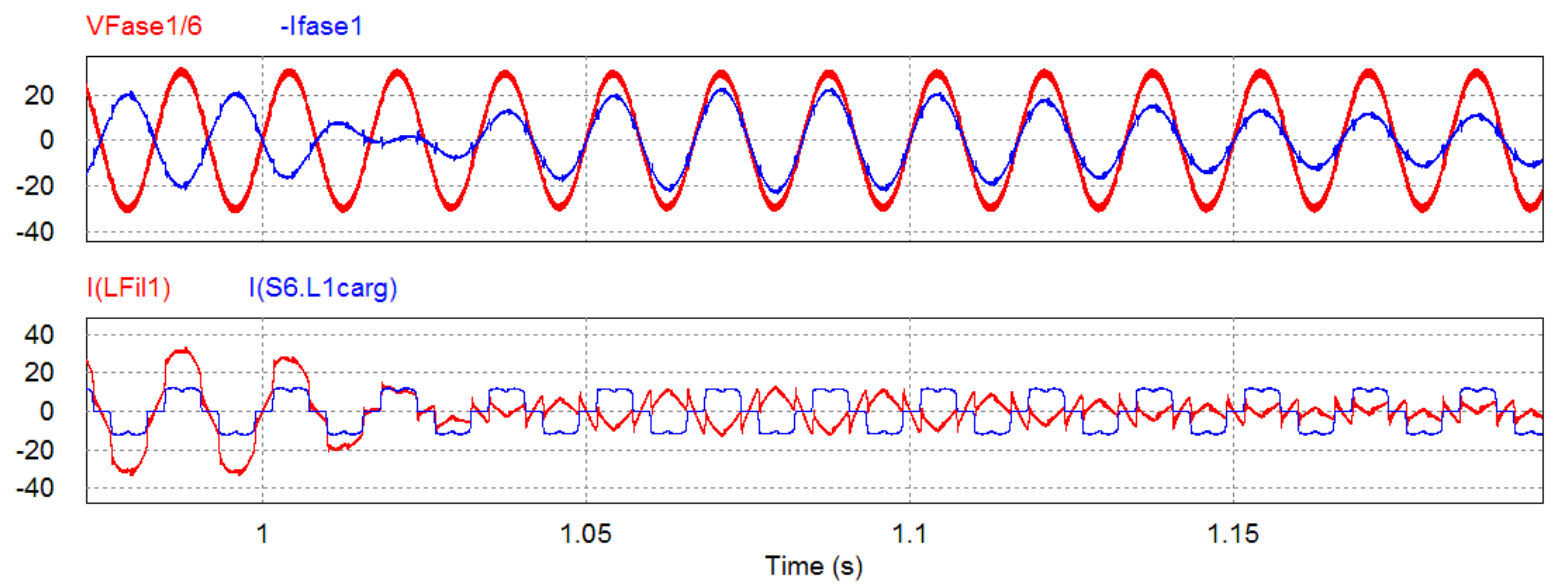

Fig. 19 No-linear load: grid voltage and current (phase 1), load current and output inverter current (phase 1). 


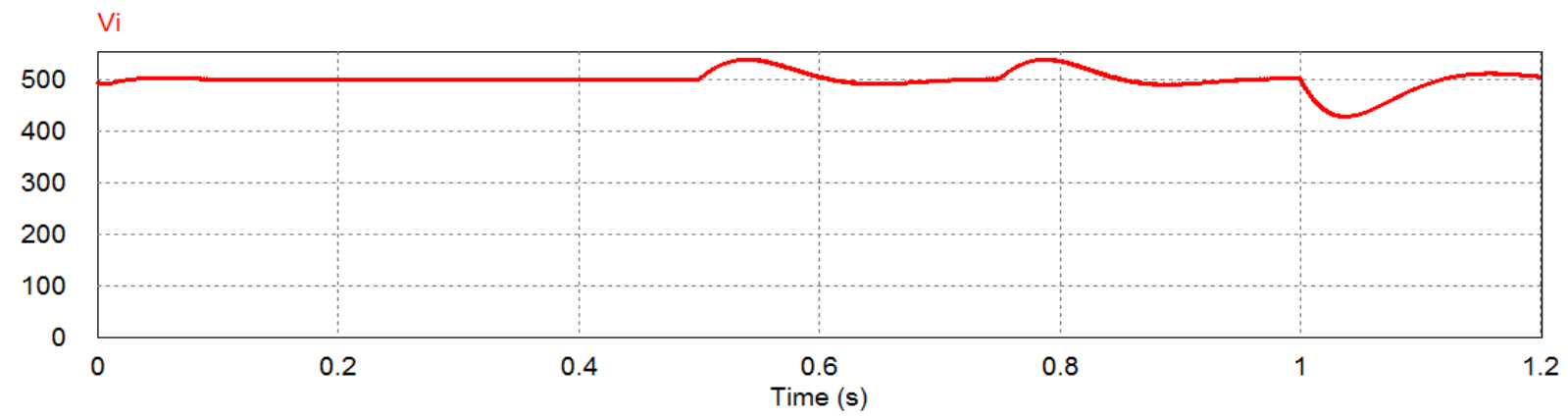

Fig. 20 Behavior of the voltage $V_{i}$.
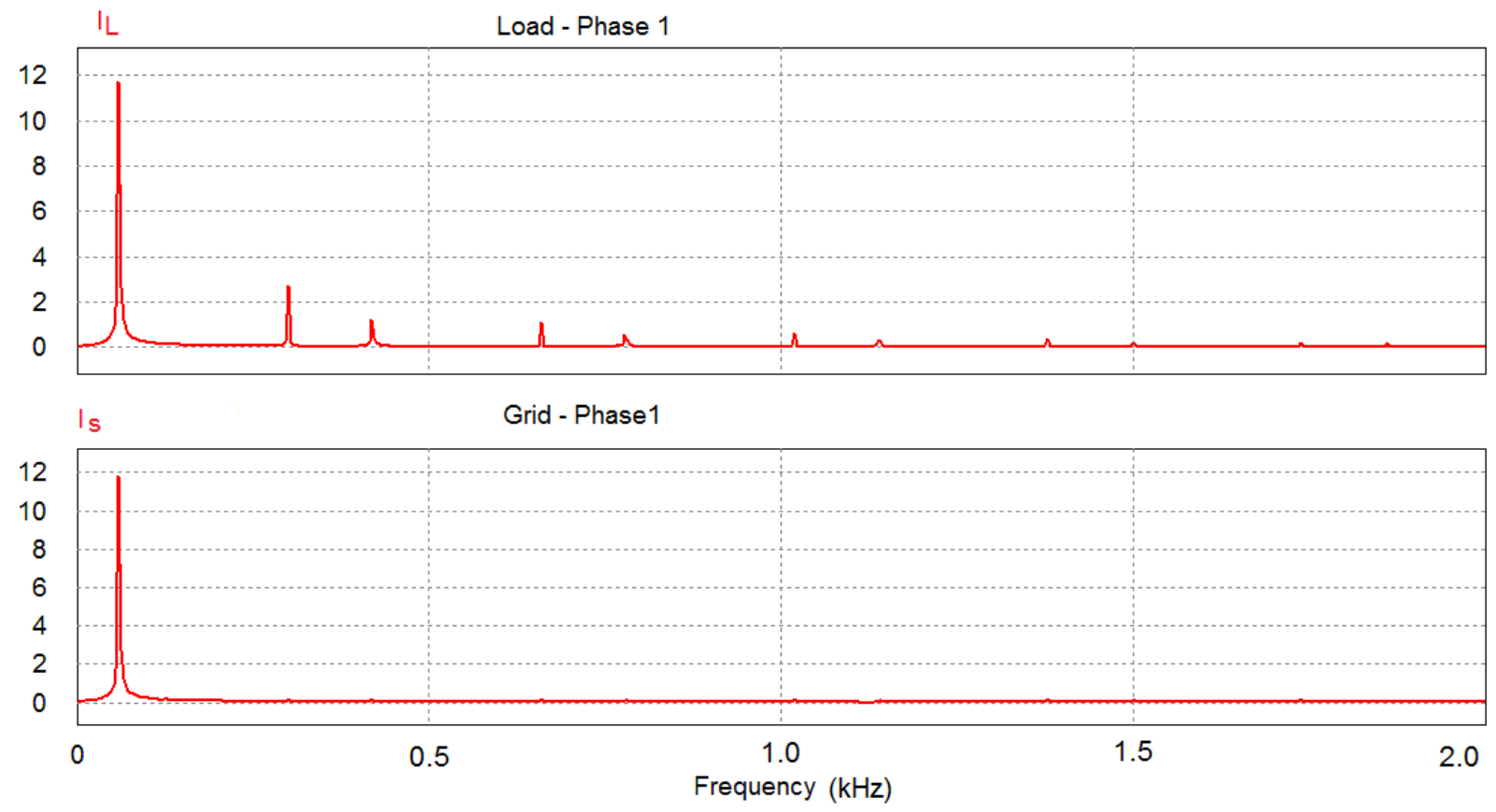

Fig. 21 Current spectrum harmonic.

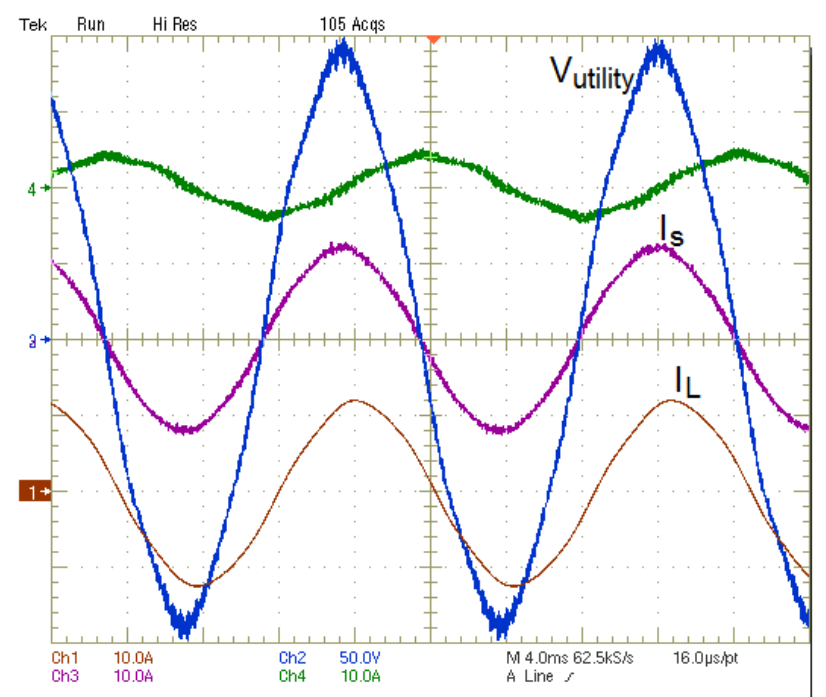

Fig. 22 Operation as active filter: utility voltage $\left(V_{U t i l i t}\right)$, utility current $\left(I_{S}\right)$, load current $\left(I_{L}\right)$, inverter current (green) in phase 1 with linear load.

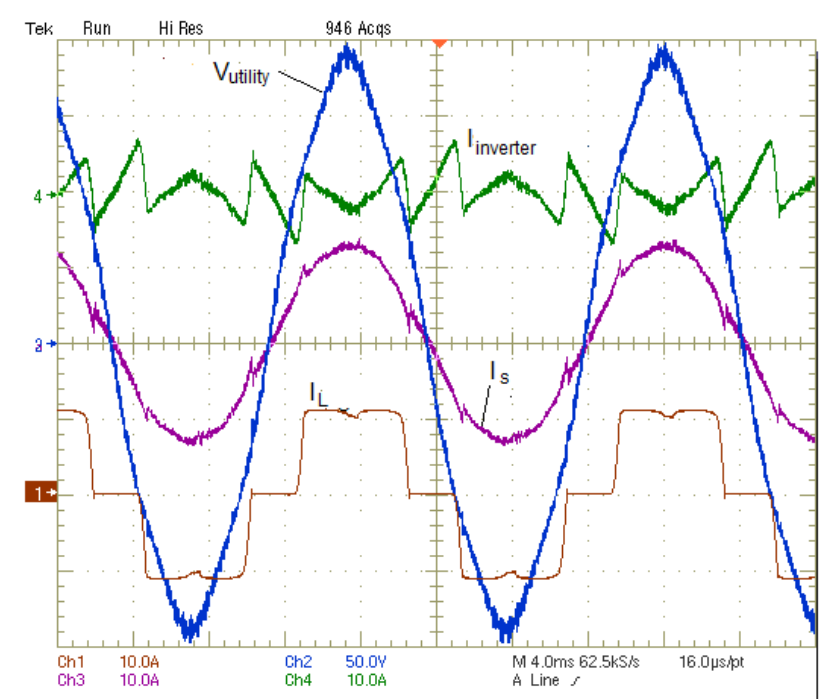

Fig. 23 Operation as active filter: utility voltage $\left(V_{U t i l i t}\right)$, utility current $\left(I_{S}\right)$, load current $\left(I_{L}\right)$, inverter current: phase1 with no-linear load. 


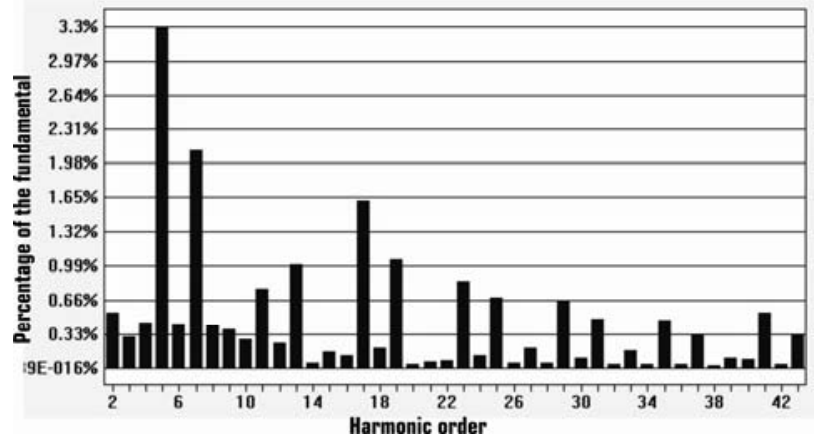

Fig. 24 Utility current harmonic spectrum in the phase 1 for non-linear load.

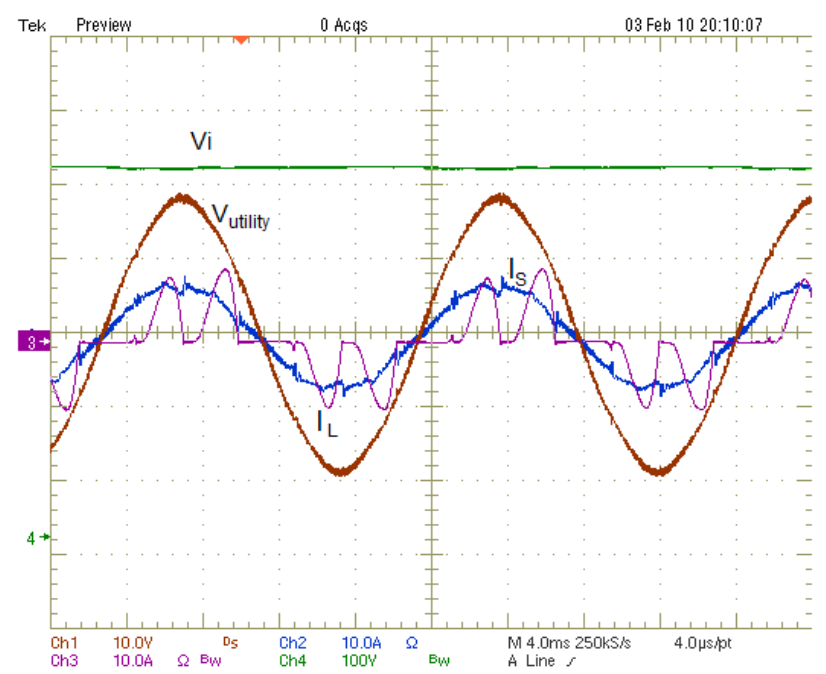

Fig. 25 Operation only as active filter: utility voltage $\left(V_{U t i l i t y}\right)$, utility current $\left(I_{S}\right)$, load current $\left(I_{L}\right)$ in phase 1: input voltage $\left(V_{i}\right)$ whit no-linear load.

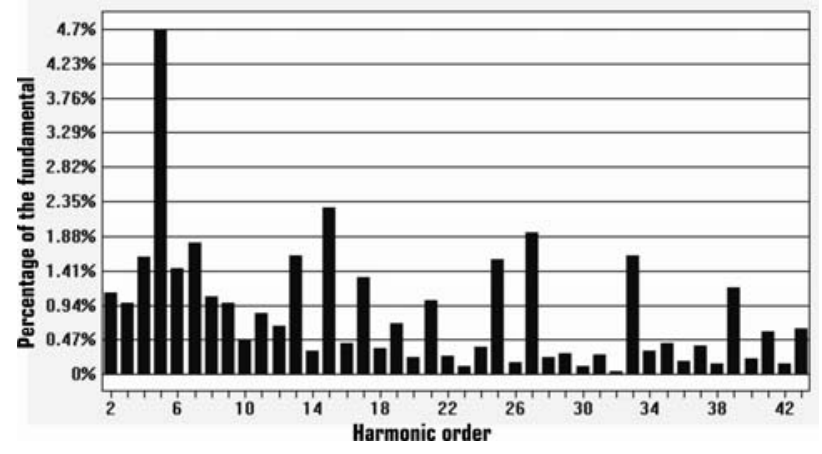

Fig. 26 Utility current harmonic spectrum in the phase 1.

Fig. 28 presents, for phase 1, with a linear load, the utility voltage $\left(V_{U t i l i t y}\right)$ and utility current $\left(I_{S}\right)$, the current supplied by the PV array $\left(I_{p v}\right)$ and the voltage $V_{i}$. In this situation, the system operates as an active filter, providing energy to the grid. In addition, it is verified the dc bus voltage $V_{i}$ remains around the maximum power point voltage, i.e., $463 \mathrm{~V}$.

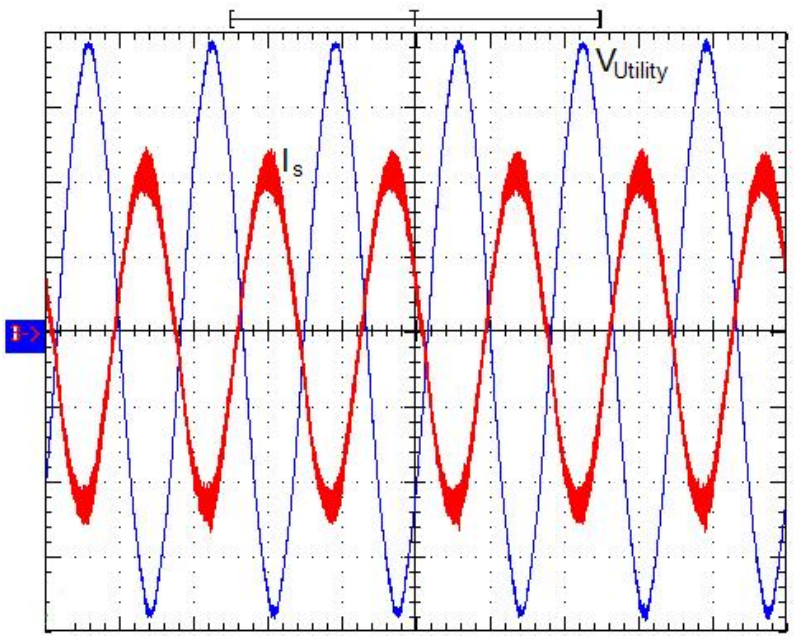

Fig. 27 Utility current $\left(I_{S}\right)$ and utility voltage $\left(V_{U t i l i t}\right)(\mathrm{Ch} 1$ 20A/div and Ch2 50V/div).

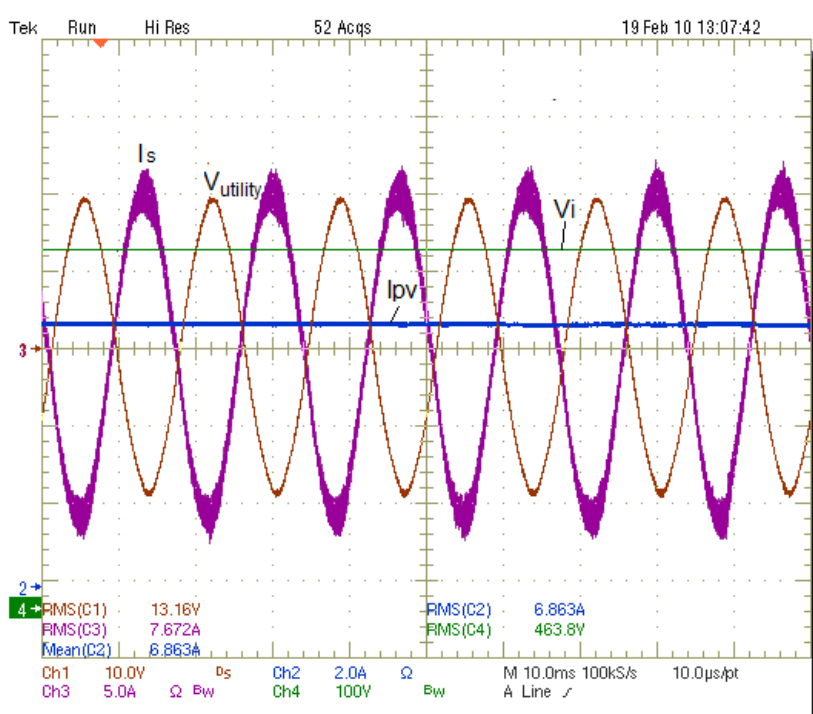

Fig. 28 Utility current $\left(I_{S}\right)$, utility voltage $\left(V_{U t i l i t y}\right), P V$ array curent $\left(I_{p v}\right)$ and voltage $V_{i}$.

Finally, Fig. 29 presents the performance of the utility voltage and utility current $(T H D=2.78 \%$ and PF $=0.978$ ) for a non-linear load connected between the PV system and the commercial electric grid. The current supplied by the PV array $\left(I_{p v}\right)$ is also shown in the figure. The last test scenario was employed to validate the performance of the system for current harmonic compensating and power flow controlling. Thus, it is possible to employ the proposed structure for processing the PV energy generation, in grid connected applications, as well as, in power factor correction. The efficiency curve of the whole system is shown in Fig. 30. We can note that from $20 \%$ of the load the efficiency is 


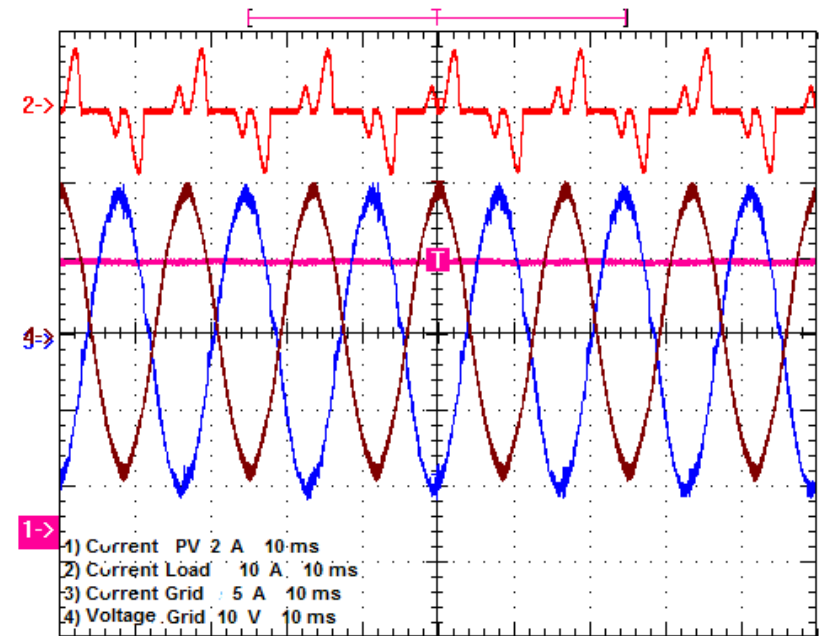

Fig. 29 Utility current, utility voltage, PV array current, and load current.

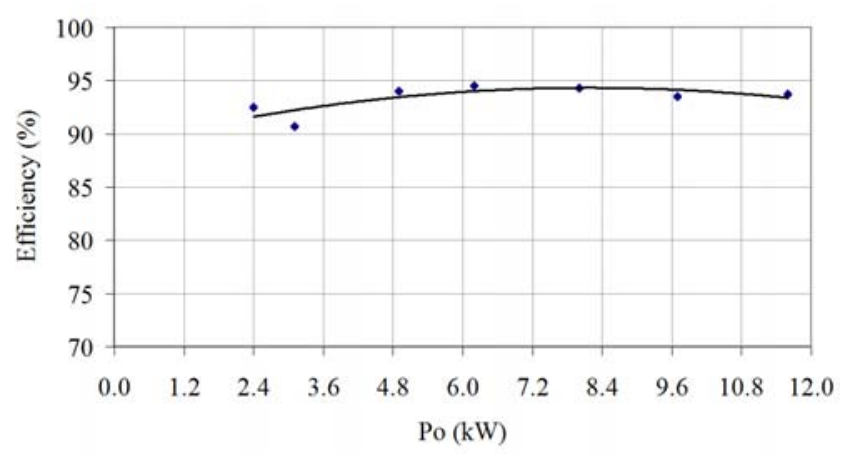

Fig. 30 Efficiency curve of the whole system.

kept above $92 \%$. In the ratting power the efficiency achieves around 94\%. Using the new generation switches (gallium IGBT and silicon carbid diode), the efficiency of the whole system can be improved.

\section{Conclusions}

Since renewable energy source became a reality, several topologies and control techniques were developed in order to ensure the quality of the grid current, reducing its THD and raising the power factor. This paper has presented, in a simple way, the modeling and control strategy using $d q 0$ transformation of a three-phase PWM inverter to be employed in a grid-connected photovoltaic generation system. The main focus of this work consists on the design of a dual function system that would provide solar generation and works as an active power filter, compensating unbalances of power and the reactive

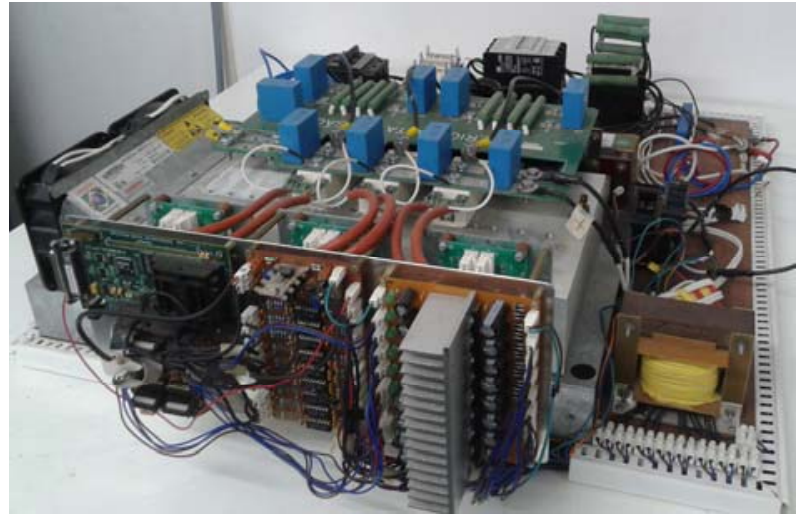

Fig. 31 Photo of the implemented prototype.

power generated by others loads connected to the system. These cited features are quite required for the power quality maintenance, since the grid-connected systems are, today, following some new trends come from the smart grid concept.

It is important to emphasize that for any situations the power factor is always high and the currents present low harmonic distortion.

Due to a little variation of the temperature in the region where the PV panels is implemented, an input voltage clamping technique is used to assure the MPP (maximum power point) of the PV panels.

Validating the structure operation some simulation and experimental results were presented and they show the viability of the proposed modeling, as well as the control strategy used for the PV grid-connected systems.

The non-linear load tested consists of a three-phase bridge rectifier with $\mathrm{RC}$ output. All the results presented show, for any situation, that the waveform of the current is quite sinusoidal and with high power factor.

Fig. 31 shows the photo of the implemented three-phase converter prototype, highlighting its main components.

\section{Acknowledgments}

The authors would like to thank the $\mathrm{CNPq}$ and FINEP by the financial support.

\section{References}

[1] O. Wasynczuk, N.A. Anwah, Modeling and dynamic 
performance of a self-commutated photovoltaic inverter system, IEEE Transactions on Energy Conversion 4 (3) (1989) 322-328.

[2] W. Bohrer, M. Carpita, T. Ghiara, L. Puglisi, A flexible control strategy to interface solar system with privileged load and utility line, in: Mediterranean Electrotechnical Conference Proceedings, Integrating Research, Industry and Education in Energy and Communication Engineering, MELECON'89, Lisbon, Apr. 11-13, 1989, pp. 25-30.

[3] N. Mohan, A novel approach to minimize line-current harmonics in interfacing renewable energy sources with 3-phase utility systems, in: Seventh Annual Applied Power Electronics Conference and Exposition, APEC'92, Boston, USA, 1992, pp. 852-858.

[4] S. Nonaka, A novel three-phase sinusoidal PWM voltage source inverter and its application for photovoltaic power generation system, in: Proceedings of the Power Conversion Conference, Nagaoka, 1997, pp. 755-758.

[5] I.H. Hwang, K.S. Ahn, H.C. Lim, S.S. Kim, Design, development and performance of a $50 \mathrm{~kW}$ grid connected PV system with three phase current-controlled inverter, in: Conference Record of the 28th IEEE Photovoltaic Specialists Conference, 2000, pp. 1664-1667.

[6] C. Cecati, A. Dell'Aquila, M. Liserre, A novel three-phase single-stage distributed power inverter, IEEE Transactions on Power Electronics 19 (5) (2004) 1226-1233.

[7] I.S. Kim, Robust maximum power point tracker using sliding mode controller for three phase grid connected photovoltaic system, Solar Energy 81 (2007) 405-414.

[8] Y. Chen, K. Ma Smedley, One-cycle-controller three-phase grid-connected inverters and their parallel operation, IEEE Transctions on Industry Applications 44 (2) (2008) 663-671.

[9] R.R. Sawant, M.C. Chandorkar, A multifunctional four-leg grid-connected compensator, IEEE Transctions on Industry Applications 45 (1) (2009) 249-259.

[10] M.C. Cavalcanti, G.M.S. Azevedo, K.C. Oliveira, B.A. Amaral, F.A.S. Neves, Z.D. Lins, A grid connected photovoltaic generation system with harmonic and reactive power compensation, in: 8th Power Electronics Brazilian Conference, COBEP, Recife, Brazil, 2005, pp. 135-140.

[11] L. Liu, H. Li, Y. Xue, A coordinated active and reactive control strategy for grid-connected cascaded photovoltaic (PV) system in high voltage high power applications, in: IEEE Applied Power Electronics Conference and Exposition, APEC 2013, pp. 1301-1308, 2013.

[12] V.H. Leela, S.T. Subha, Control of power converter for power quality improvement in a grid connected PV system, in: IEEE International Conference on Circuits, Power and Computing Technologies, ICCPCT 2013, pp. 26-30, 2013.

[13] R. Demonti, Photovoltaic panels electric energy management, Ph.D. Thesis, Florianópolis, INEP, UFSC, Brazil, 2003.

[14] M.J. Case, J.J. Schoeman, A mínimum component photovoltaic array maximum power point tracker, in: European Space Power Conference, Granz, Austria, 1992, pp. 107-110.

[15] D. Borgonovo, Modelling and control of the three-phase PWM rectifier using park transformation, Master Thesis, INEP, UFSC, Florianópolis, Brazil, 2001.

[16] A.S. Morais, I. Barbi, Power Redistributor applied to distribution transformers of the electrical energy, in: XVI Brazilian Automation Conference, CBA, Salvador, Brazil, 2006, pp. 334-339.

[17] R. Kumar, A. Mohanty, S.R. Mohanty, N. Kishor, Power quality improvement in 3- $\phi$ grid connected photovoltaic system with battery storage, in: IEEE International Conference on Power Electronics, Drives and Energy Systems, Dec. 2012, pp. 1-6. 